\title{
Experiments with low-T potassic carbonatitic melts, fluids and diamonds.
}

Jones A P, Dobson D, Milledge H J, T Taniguchi, Y Litivin, Genge M J, and Rabe R.

Haskel High Pressure Laboratory, Department of Geological Sciences, University College London, Gower Street, London, UK WC1E 6BT. email ucfbhaj@ucl.ac.uk

We present comprehensive new data on alkali carbonate systems obtained through a programme of high pressure experiments, using piston cylinder, multianvil press and in-situ synchrotron techniques; we have completed new phase diagrams for alkalicarbonates to high-P and measured their viscosities and densities as a function of both $\mathrm{P}$ and $\mathrm{T}$ (Jones et al, 1995; Dobson et al, 1996: summary Table 1). The role of alkalies can have a major effect in determining low temperature melt compositions (Genge et al, 1995). We demonstrate the high mobility of independent alkali carbonatite melts at temperatures well below the solidus of peridotitic mantle (silicate) rocks and similarly below propsed continental / shield geotherms (Fig. 1).

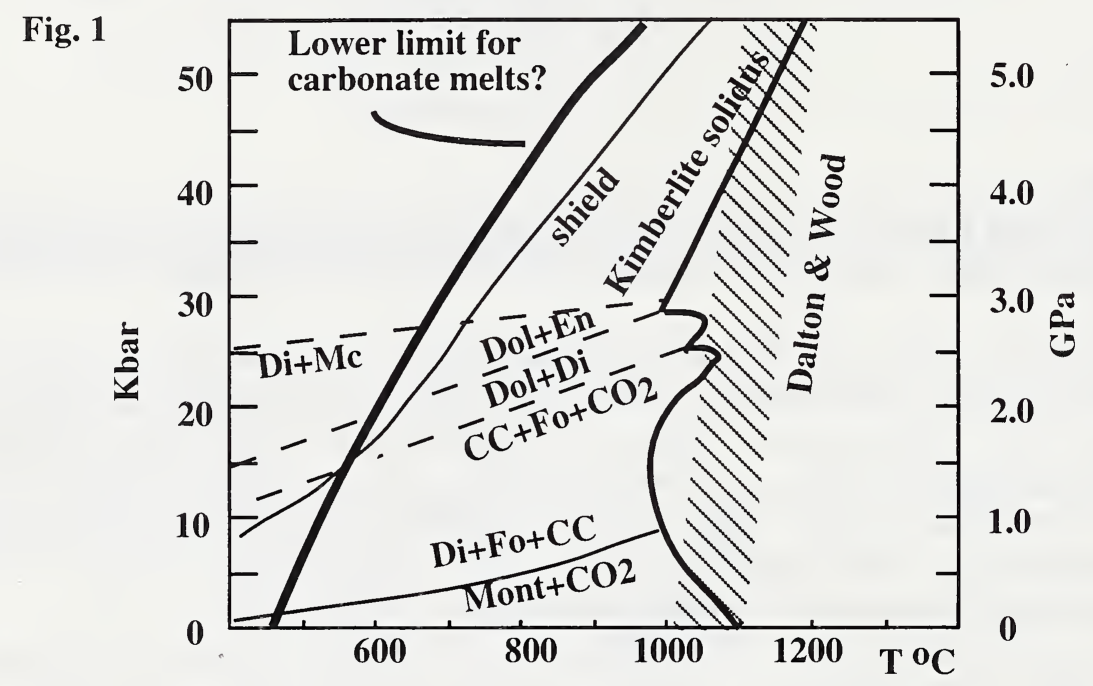

The composition of potassic-magnesian carbonates have particularly low melt temperatures over a wide range of pressures, and have high solute capacities for volatile elements, such as water and halogens. This bulk composition is similar to the fluids in 'coated stone' type diamonds. At higher pressures (8-10 GPa) the same $\mathrm{K}-\mathrm{Mg}$ carbonate can transform graphitic carbon directly to diamond (Taniguchi et al, 1996). Limited experiments with $\mathrm{Na}-\mathrm{Mg}$ carbonate melts show similar behaviour to the $\mathrm{K}-\mathrm{Mg}$ melts, both in terms of low-T behaviour and diamond growth potential. We propose a dynamic model for diamond formation from carbonatitic melts; changes of local mantle conditions, including oxygen fugacity and bulk composition through localised reactions could both nucleate and crystallise diamond directly from carbonate melts. Stable isotope data from our carbonate-diamond experiments suggest there is no major isotopic fractionation during this transformation of carbon; this is in accord with the coincidence for carbon isotope signatures between natural carbonatites and most diamonds $\left(\delta^{13} \mathrm{C}\right.$ ca. $\sim-5 \%$ ). 


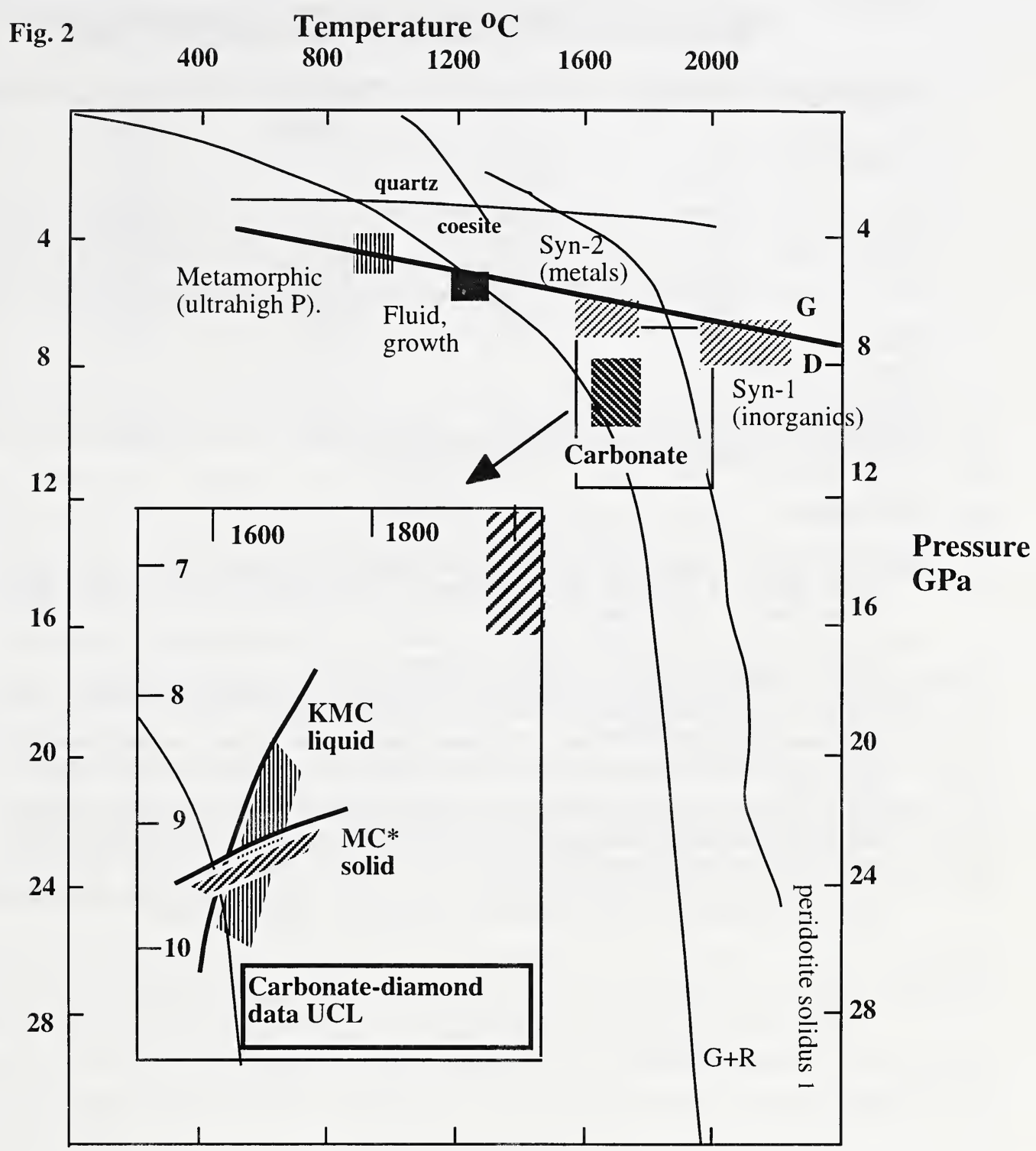

Summary diagram of carbonate-diamond experiments at UCL in relation to other documented diamond formation conditions, mineral equilibria and peridotite solidus data.

Finally, there are clear petrogenetic paths between these carbonatitic melts and kimberlites; the high alkali contents also suggest a number of links (though less clear) between kimberlites, carbonatites and even with mantle metasomatic processes including the MARID suite (eg: Jones, 1989). 
Table 1: In-situ physical data for super-liquidus carbonate melts measured at P-T with synchrotron (ref: Dobson et al, 1996)

\begin{tabular}{|lllll|}
\hline Composition & $\mathrm{P}(\mathrm{GPa})$ & $\mathrm{T}\left({ }^{\circ} \mathrm{C}\right)$ & $\begin{array}{l}\text { density } \\
(\mathrm{g} / \mathrm{cm} 3)\end{array}$ & $\begin{array}{l}\text { viscosity } \\
(\mathrm{Pas})\end{array}$ \\
$\mathrm{K} 2 \mathrm{Mg}\left(\mathrm{CO}_{3}\right) 2$ & 3.0 & 800 & & 0.036 \\
& 3.0 & 900 & & 0.022 \\
& 5.5 & 1200 & & 0.006 \\
$\mathrm{~K}_{2} \mathrm{Ca}\left(\mathrm{CO}_{3}\right) 2$ & 2.5 & 950 & 2.75 & 0.032 \\
& 2.5 & 1150 & 2.58 & 0.018 \\
& 4.0 & 1050 & 2.80 & 0.023 \\
REEcarb* & 3.0 & 530 & 4.10 & 0.155 \\
$(\mathrm{Jones}$ and & & & & \\
Wyllie, 1983) & 4.0 & 1500 & 3.10 & 0.023 \\
$\mathrm{~K} 2 \mathrm{CO} 3$ & & & \\
\hline
\end{tabular}

*REE-rich carbonate melts can have high densities.

\section{References}

Dobson D, Jones A P, Rabe R, Sekine T, Kurita K, Taniguchi T, Kondo T, Kato T, Shimomura $\mathrm{O}$ and Urakawa S. (1996) In-situ measurement of viscosity and density of carbonate melts at high pressure. Earth Planet.Sci.Lett.143, 207-215.

Jones A P , Dobson D and Genge M (1995) Comment on physical properties of carbonatite magmas inferred from molten salt data.. Geol. Mag.132, 121.

Jones A P (1989) Upper mantle enrichment by kimberlitic or carbonatitic magmatism. In ( $\mathrm{K}$ Bell ed) Carbonatites, Allen and Unwin, New York, 448-463.

Jones A P and Wyllie P J (1983) Low temperature glass quenched from a synthetic rare earth carbonate: implications for the origin of the Mountain Pass Deposit. Econm. Geol, 78, 1721-1723.

Taniguchi T, Dobson D, Jones A P, Rabe R and Milledge H J. (1996) Synthesis of cubic diamond in the graphite- $\mathrm{K} 2 \mathrm{Mg}(\mathrm{CO}) 2$ systems at high pressure of 9-10 GPa region. Jour. Materials Research, 11, 2622-2632.

Genge M, Jones A P and Price G D (1995) Spectroscopic studies of carbonate glasses and a model for carbonate melt structure. Geochim. Cosmochim. Acta 59, 927-937 